\section{For Primary Prevention, Should All \\ Moderate- to High-Risk Patients Be Considered Candidates for Acetylsalicylic Acid?}

\section{THE "PRO" SIDE}

Acetylsalicylic acid (ASA) was first investigated for use in primary prevention of cardiovascular disease in the $1980 \mathrm{~s}^{1}{ }^{1}$ Since that time, more than 160000 individuals have participated in studies of ASA for primary prevention. ${ }^{2}$ On the basis of available data, the American College of Cardiology/American Heart Association guidelines for primary prevention (2019) recommend that ASA be considered for prevention of atherosclerotic cardiovascular disease in patients deemed to be at high risk without elevated bleeding risk. ${ }^{3}$ Similarly, the guidelines of Hypertension Canada (2020) and the Canadian Diabetes Association (2018) both recommend that ASA be considered to reduce vascular risk in these populations in the absence of elevated bleeding risk. ${ }^{4,5}$

In 2018, three large primary prevention trials comparing ASA with placebo were published (ARRIVE, ${ }^{6}$ ASCEND, ${ }^{7}$ ASPREE $^{8}$ ). The ASCEND study, which compared ASA with placebo in participants with diabetes, found a statistically significant reduction in the primary composite outcome (nonfatal myocardial infarction, nonfatal stroke, transient ischemic attack, or vascular-related death) after a median of 7.4 years $(8.5 \%$ versus $9.6 \%, p=0.01) .{ }^{7}$ In the ARRIVE and ASPREE studies, both of which compared ASA with placebo in primary prevention populations, trends toward benefit in the prevention of cardiovascular disease did not reach statistical significance. ${ }^{6,9}$ At the same time, each of these studies found a statistically significant increase in the risk of bleeding with ASA, relative to placebo (for ARRIVE, $0.97 \%$ versus $0.46 \%$; for ASCEND, 4.1\% versus 3.2\%; for ASPREE, 3.8\% versus 2.8\%). ${ }^{6-9}$

Some might interpret these data to mean that ASA should not be used for primary prevention; however, the lack of a statistically significant benefit in the ARRIVE and ASPREE studies must be considered in the context of the much lower than expected rate of cardiovascular outcomes. Over the 5-year duration of the ARRIVE study, the primary composite cardiovascular outcome (myocardial infarction, stroke, cardiovascular death, unstable angina, transient ischemic attack) occurred in $4.29 \%$ and $4.48 \%$ of participants randomly assigned to receive ASA and placebo, respectively, well below the originally expected event rates of $11.4 \%$ (ASA) and $13.4 \%$ (placebo). ${ }^{6}$ Similarly, over the 4.7 years of the ASPREE study, the rates of the composite cardiovascular outcome (fatal coronary heart disease, nonfatal myocardial infarction, fatal or nonfatal stroke, hospital admission for heart failure) were $4.7 \%$ and $4.9 \%$ among participants randomly assigned to ASA and placebo, respectively. ${ }^{8}$
Thus, the lack of benefit seen in these low-risk populations is not necessarily applicable to the population with moderate to high risk.

Multiple systematic reviews and meta-analyses incorporating these new data have been published, many of which highlight a benefit in prevention of nonfatal cardiovascular events at the cost of excess bleeding. ${ }^{10}$ One such meta-analysis, performed by Zheng and Roddick, ${ }^{2}$ found statistically significant reductions in the composite cardiovascular outcome (cardiovascular mortality, nonfatal myocardial infarction, nonfatal stroke; absolute risk reduction [ARR] 0.41\%, $95 \%$ confidence interval $[\mathrm{CI}] 0.23 \%-0.59 \%$, number needed to treat [NNT] 241), myocardial infarction (ARR 0.28\%, 95\% CI 0.05\%$0.47 \%$, NNT 361), and ischemic stroke (ARR 0.19\%, 95\% CI $0.06 \%-0.30 \%$, NNT 540). A greater reduction in the primary composite cardiovascular outcome was seen in the subgroups with high risk of cardiovascular disease (ARR 0.63\%, 95\% CI 0.18\%$1.03 \%$, NNT 160) and with diabetes (ARR 0.65\%, 95\% CI 0.09\%$1.17 \%$, NNT 153). ${ }^{2}$ These benefits of ASA in higher-risk populations are on par with the benefits of statins when used for primary prevention, for which the NNTs for myocardial infarction, stroke, and cardiovascular death are 123,263 , and 233, respectively. ${ }^{11}$ Not unexpectedly, the same meta-analysis found an increase in major bleeding (absolute risk increase [ARI] 0.47\%, 95\% CI $0.34 \%-0.62 \%$, number needed to harm 210$)^{2}$

Although direct comparison of the benefits and risks shows similar numeric values for ARRs and ARIs, the clinical significance of these events is not equivalent. The rate of fatal bleeding with ASA is extremely low $(0.29 \%$ in the ASPREE study), as is the rate of disability following major hemorrhagic events. ${ }^{9,12}$ In a prospective cohort analysis of bleeding events secondary to long-term antiplatelet use, the rate of disability after a bleeding event was estimated at $0.5 \% .^{12}$ By comparison, in-hospital and 1-year mortality rates after acute myocardial infarction have been estimated at $4.0 \%$ and $7.6 \%$, respectively, and hospital admission for heart failure at 4 years after acute myocardial infarction has been estimated at $12 \%{ }^{13,14}$ After a stroke, the risk of in-hospital mortality has been estimated at $2 \%$, and 10 -year post-stroke disability rates have been estimated as $12.2 \%$ for moderate disability, $14.4 \%$ for severe disability, and $28.0 \%$ for cognitive impairment. ${ }^{15,16}$ Thus, the differing clinical outcomes after cardiovascular and bleeding events must lead us away from interpreting these similar ARRs and ARI as equivalent.

Finally, patient preference plays an important role in treatment selection. Although few data are available on patient preferences regarding ASA for primary prevention, extensive data exist on patient preferences concerning antithrombotic agents for atrial fibrillation. A narrative systematic review found that patients with or without atrial fibrillation considered the outcome of disabling stroke worse than death. To prevent a single stroke, patients were willing to accept multiple serious bleeding events, with a reported acceptable range of 
2 to more than 33 serious bleeding events per stroke prevented..$^{17}$ Thus, it is apparent that patients do not place equal value on cardiovascular events and bleeding events.

Overall, while ASA used in the primary prevention of cardiovascular disease appears to have a similar ARR for cardiovascular outcomes as its ARI for major bleeding, the cardiovascular outcomes are clinically more significant than the bleeding outcomes, and are valued as such by patients. ASA for primary prevention may not be appropriate for everyone, but it should be considered for all individuals at moderate to high risk of cardiovascular disease.

\section{References}

1. Raber I, McCarthy CP, Vaduganathan M, Bhatt DL, Wood DA, Cleland JGF, et al. The rise and fall of aspirin in the primary prevention of cardiovascular disease. Lancet. 2019;393(10186):2155-67.

2. Zheng SL, Roddick AJ. Association of aspirin use for primary prevention with cardiovascular events and bleeding events: a systematic review and meta-analysis. JAMA. 2019;321(3):277-87.

3. Arnett DK, Blumenthal RS, Albert MA, Buroker AB, Goldberger ZD, Hahn EJ, at al. 2019 ACC/AHA guideline on the primary prevention of cardiovascular disease: a report of the American College of Cardiology/American Heart Association Task Force on Clinical Practice Guidelines. Circulation. 2019;140(11):e596-e646.

4. 2020 hypertension highlights. A practical guide informed by the Hypertension Canada guidelines for the diagnosis, risk assessment, prevention, and treatment of hypertension. Markham (ON): Hypertension Canada; [cited 2019 Nov 16]. Available from: https://hypertension.ca/wp-content/ uploads/2018/07/Hypertension-Guidelines-English-2018-Web.pdf

5. Diabetes Canada Clinical Practice Guideline Expert Committee. Diabetes Canada 2018 clinical practice guidelines for the prevention and management of diabetes in Canada. Can J Diabetes. 2018;42(Suppl 1): S1-S325.

6. Gaziano JM, Brotons C, Coppolecchia R, Cricelli C, Darius H, Gorelick $\mathrm{PB}$, et al. Use of aspirin to reduce risk of initial vascular events in patients at moderate risk of cardiovascular disease (ARRIVE): a randomised, doubleblind, placebo-controlled trial. Lancet. 2018;392(10152):1036-46.

7. ASCEND Study Collaborative Group; Bowman L, Mafham M, Wallendszus K, Stevens W, Buck G, Barton J, et al. Effects of aspirin for primary prevention in persons with diabetes mellitus. N Engl J Med. 2018;379(16):1529-39.

8. McNeil JJ, Woods RL, Nelson MR, Reid CM, Kirpach B, Wolfe R, et al.; ASPREE Investigator Group. Effect of aspirin on disability-free survival in the healthy elderly. N Engl J Med. 2018;379(16):1499-508.

9. McNeill JJ, Wolfe R, Woods RL, Tonkin AM, Donnan GA, Nelson MR, et al.; ASPREE Investigator Group. Effect of aspirin on cardiovascular events and bleeding in the healthy elderly. N Engl J Med. 2018;379(16):1509-18.

10. Freige $\mathrm{C}$, Wright MD. CADTH rapid response report: summary of abstracts. Acetylsalicylic acid for primary prevention of cardiovascular events: clinical effectiveness and guidelines. Ottawa (ON): Canadian Agency for Drugs and Technology in Health; 2019 [cited 2019 Nov 16]. Available from: https://www.cadth.ca/sites/default/files/pdf/htis/2019/RB1368\%20ASA\%2 0for\%20primary\%20prevention\%20of\%20CVD\%20Final.pdf

11. Chou R, Dana T, Blazina I, Daeges M, Jeanne TL. Statins for prevention of cardiovascular disease in adults: evidence report and systematic review for the US Preventive Services Task Force. JAMA. 2016;316(19):2008-24.

12. Li L, Geraghty OC, Mehta Z, Rothwell PM; Oxford Vascular Study. Agespecific risks, severity, time course, and outcome of bleeding on long-term antiplatelet treatment after vascular events: a population-based cohort study. Lancet. 2017;390(10093):490-9.

13. Fox KAA, FitzGerald G, Puymirat E, Huang W, Carruthers K, Simon T, et al. Should patients with acute coronary disease be stratified for management according to their risk? Derivation, external validation and outcomes using the updated GRACE risk score. BMJ Open. 2014;4(2):e004425.

14. McAllister DA, Halbesma N, Carruthers K, Denvir M, Fox KA. GRACE score predicts heart failure admissions following acute coronary syndrome. Eur Heart J Acute Cardiovasc Care. 2015;4(2):165-71.
15. Gattringer T, Posekany A, Niederkorn K, Knoflach M, Poltrum B, Mutzenback S, et al. Predicting early mortality of acute ischemic stroke. Stroke. 2019;50(2):349-56.

16. Crichton SL, Bray BD, McKevitt C, Rudd AG, Wolfe CD. Patient outcomes up to 15 years after stroke: survival, disability, quality of life, cognition and mental health. J Neurol Neurosurg Psychiatry. 2016;87(10):1091-8.

17. Loewen PS, Ji AT, Kapanen A, McClean A. Patient values and preferences for antithrombotic therapy in atrial fibrillation. A narrative systematic review. Thromb Haemost. 2017;117(6):1007-22.

Jennifer Bolt, BScPharm, ACPR, PharmD, MHA

Research \& Development Pharmacist - Seniors Care/Pharmacy

Practice Models

Department of Pharmacy Services, Interior Health Authority

Kelowna, British Columbia

Clinical Assistant Professor (Partner)

Faculty of Pharmaceutical Sciences, University of British Columbia

Vancouver, British Columbia

Competing interests: None declared.

\section{THE "CON" SIDE}

The efficacy of acetylsalicylic acid (ASA) for prevention of vascular events in patients with existing cardiovascular disease is well established. ${ }^{1}$ Among those patients, the focus lately has been on the extent to which newer options (e.g., P2Y12 inhibitors, non-vitamin $\mathrm{K}$ antagonist oral anticoagulants) can augment or displace ASA..$^{2-5}$ In parallel, many large randomized controlled trials (RCTs) have investigated the benefits and harms of ASA in various primary prevention populations (patients without clinically manifest coronary heart disease, cerebrovascular disease, or peripheral artery disease). Meta-analyses of these trials have included more than 165000 patients with over 1 million patientyears of follow-up and 3 large recent RCTs in populations about which there was residual uncertainty (patients with diabetes, the elderly, and those needing high-risk primary prevention). ${ }^{6,7}$ If you believe, as I do, that RCTs are the most powerful methodology to detect cause-and-effect relationships between drugs and outcomes, then there is ample basis for confidence that the role of ASA in primary prevention is minor and diminishing.

Simply put, there is high-quality evidence that many primary prevention patient populations should not be considered candidates for ASA, including the following:

Primary prevention patients 70 years of age or older: The recent ASPREE trial showed that in patients 70 years or older, relative to placebo, ASA did not reduce cardiovascular events, ${ }^{8}$ dementia, or physical disability, ${ }^{9}$ caused major bleeds (hazard ratio [HR] 1.38, 95\% confidence interval [CI] 1.18-1.62, number needed to harm $[\mathrm{NNH}] 98$ for 4.7 years), and increased all-cause mortality (HR 1.14, 95\% CI 1.01-1.29, NNH 142 for 4.7 years), a major contributor to which was cancer death 
(HR 1.31, 95\% CI 1.0-1.56, NNH 137 for 4.7 years). ${ }^{10}$ This trial, one of the largest RCTs ever conducted, strongly indicates that initiating ASA for primary prevention in people aged 70 years or older is inappropriate. It also raises the question of whether, for patients who start the drug at a younger age, ASA should be stopped when they reach that age. This choice should be based on the strength of the rationale for starting ASA in the first place, and the preponderance of current evidence discussed below indicates that the rationale is weak for most patient groups.

Primary prevention patients who are receiving anticoagulants: We now have solid evidence that ASA plus oral anticoagulant (OAC) causes more major bleeding than OAC alone, and the combination provides no additional benefit in patients with atrial fibrillation who have prior acute coronary syndrome. ${ }^{4,11-14}$ It is even more difficult to justify ASA in anticoagulated patients with atrial fibrillation in the absence of coronary artery disease. In primary prevention, patients who do not have atrial fibrillation and who are receiving an anticoagulant for some other reason (e.g., venous thromboembolism) have increased risk of major bleeding with combined ASA and OAC. In addition, several trials showing that OACs prevent coronary events at least as effectively as ASA ${ }^{15-17}$ imply that ASA causes net harm for patients who are taking an OAC for non-atrial fibrillation conditions. Antiphospholipid syndrome with arterial thrombosis is a notable possible exception to this. ${ }^{18}$

Many patients with diabetes: Previous trials showed lack of efficacy of ASA for primary prevention in patients with diabetes. ${ }^{19,20}$ The recent ASCEND trial showed fewer serious vascular events (rate ratio 0.88, 95\% CI 0.79-0.97, NNT 91 for 7.4 years) and excess major bleeding (rate ratio $1.29,95 \% \mathrm{CI}$ 1.09-1.52, NNH 112 for 7.4 years) with ASA relative to placebo. ${ }^{21}$ Meta-analysis of all 7 trials of ASA in patients with diabetes revealed no benefit in terms of any specific efficacy outcome and clear evidence of harm (HR for major bleeding 1.29, 95\% CI 1.11-1.51, NNH 120 for about 7 years; HR for major gastrointestinal bleeding 1.35, 95\% CI 1.05-1.75, NNH 242 for about 7 years [where 7 years is the weighted mean follow-up duration combining JPAD, POPADAD, and ASCEND trials]). ${ }^{6}$ Use of ASA for primary prevention in patients with diabetes is therefore likely to be a highly preference-sensitive decision.

For patients outside the categories for which ASA should probably be avoided, ASA offers the possibility of reducing the risk of nonfatal myocardial infarction (HR 0.85, 95\% CI $0.76-0.95$, NNT 366 for about 6.5 years) and increasing the risk of major bleeding (HR 1.50, 95\% CI 1.33-1.69, NNH 210 for about 6.5 years; HR for gastrointestinal bleeding 1.52, 95\% CI 1.34-1.73, NNH 334 for about 6.5 years), which is independent of baseline characteristics such as sex, age, and ulcer history. The reduction in ischemic stroke and transient ischemic attack produced by ASA (HR 0.80, 95\% CI 0.71-0.89, NNT 623 for about 6.5 years) is offset by more hemorrhagic strokes (HR 1.32, $95 \%$ CI 1.12-1.55, NNH 927 for about 6.5 years), which carry a much worse prognosis. ${ }^{22}$ We now have enough evidence to be confident that ASA does not reduce the risk of fatal myocardial infarction or overall mortality, ${ }^{6,7}$ and patients interested in the potential of ASA to reduce cancer incidence or mortality will not find cause for optimism in the available evidence. ${ }^{6,7,10,21}$

However, for patients who are interested and able, their values and preferences should be respected in the choice of therapy. Several decision aids for primary prevention patients are available online, but only a minority include ASA as an option, and at present none are updated to include the full data set discussed here. ${ }^{23}$ Speaking of preferences, a UK study about pill burden found that although some people would take a no-cost, no-toxicity pill every day for the rest of their lives even if it afforded no longevity benefit, $64 \%$ would require some extension of their lifespan in order to do so. ${ }^{24}$ ASA offers neither lifespan extension nor freedom from toxic effects. Furthermore, for most patients still interested in ASA and considered to be at moderate or high cardiovascular risk on the basis of risk prediction models (e.g., Framingham, American Heart Association pooled cohort equations), ASA is probably the least effective of the risk-reduction strategies available (relative to statins, exercise, smoking cessation, blood pressure control) and carries the greatest magnitude of risk of a serious adverse drug reaction (major bleeding, intracranial hemorrhage) of any of these. ${ }^{25}$ Hence, ASA should be the last intervention that patients contemplate for primary prevention, and only if they are deemed to have moderate or high risk after these modifiable factors have been thoroughly mitigated.

Given the large amount of high-quality data now available, it is possible but unlikely that longer-term trials (if ever conducted) and patient-level meta-analyses (which are sure to be) could reveal other truths about ASA, including subpopulations in which the benefit-harm ratio is meaningfully different one way or another. As of now, the most relevant question about ASA is the following: "Is there any group of primary prevention patients who clearly are good candidates for ASA?" One such group may be patients with or without diabetes who place very high value on an extremely small chance of avoiding a nonfatal coronary event (approximately 1 in 366 chance during about 6.5 years of taking ASA), are tolerant of the risk of major bleeding (approximately 1 in 210 chance during about 6.5 years of taking ASA; occurrence of about 1.7 major bleeds per nonfatal myocardial infarction prevented), ${ }^{6,7}$ and ascribe no disutility to taking a pill daily that adds no longevity.

Clinicians and patients should continue to rely on much more effective and safe interventions than ASA, such as statins, smoking cessation, blood pressure control, and healthier lifestyles to reduce cardiovascular risk in primary prevention.

\section{References}

1. Antithrombotic Trialists' (ATT) Collaboration. Aspirin in the primary and secondary prevention of vascular disease: collaborative meta-analysis of individual participant data from randomised trials. Lancet. 2009; 373(9678):1849-60.

2. Wang Y, Wang Y, Zhao X, Liu L, Wang D, Wang C, et al.; CHANCE Investigators. Clopidogrel with aspirin in acute minor stroke or transient ischemic attack. New Engl J Med. 2013;369(1):11-19.

3. Eikelboom JW, Connolly SJ, Bosch J, Dagenais GR, Hart RG, Shestakovska O, et al.; COMPASS Investigators. Rivaroxaban with or without aspirin in stable cardiovascular disease. $N$ Engl J Med. 2017; 377(14):1319-30. 
4. Lopes RD, Hong H, Harskamp RE, Bhatt DL, Mehran R, Cannon CP, et al. Safety and efficacy of antithrombotic strategies in patients with atrial fibrillation undergoing percutaneous coronary intervention: a network meta-analysis of randomized controlled trials. JAMA Cardiol. 2019;4(8):747-55.

5. Wallentin L, Becker RC, Budaj A, Cannon CP, Emanuelsson H, Held $\mathrm{C}$, et al.; PLATO Investigators. Ticagrelor versus clopidogrel in patients with acute coronary syndromes. N Engl J Med. 2009;361(11):1045-57.

6. Zheng SL, Roddick AJ. Association of aspirin use for primary prevention with cardiovascular events and bleeding events. A systematic review and meta-analysis. JAMA. 2019;321(3):277-87.

7. Abdelaziz HK, Saad M, Pothineni NVK, Megaly M, Potluri R, Saleh M, et al. Aspirin for primary prevention of cardiovascular events. J Am Coll Cardiol. 2019;73(23):2915-29.

8. McNeil JJ, Wolfe R, Woods RL, Tonkin AM, Donnan GA, Nelson MR, et al.; ASPREE Investigator Group. Effect of aspirin on cardiovascular events and bleeding in the healthy elderly. N Engl J Med. 2018; 379(16):1509-18.

9. McNeil JJ, Woods RL, Nelson MR, Reid CM, Kirpach B, Wolfe R, et al.; ASPREE Investigator Group. Effect of aspirin on disability-free survival in the healthy elderly. $N$ Engl J Med. 2018;379(16):1499-508.

10. McNeil JJ, Nelson MR, Woods RL, Lockery JE, Wolfe R, Reid CM, et al.; ASPREE Investigator Group. Effect of aspirin on all-cause mortality in the healthy elderly. $N$ Engl J Med. 2018;379(16):1519-28.

11. Cannon CP, Bhatt DL, Oldgren J, Lip GYH, Ellis SG, Kimura T, et al; RE-DUAL PCI Steering Committee and Investigators. Dual antithrombotic therapy with dabigatran after PCI in atrial fibrillation. $N$ Engl $J$ Med. 2017;377(16):1513-24.

12. Lopes RD, Heizer G, Aronson R, Vora AN, Massaro T, Mehran R, et al.; AUGUSTUS Investigators. Antithrombotic therapy after acute coronary syndrome or PCI in atrial fibrillation. N Engl J Med. 2019;380(16): 1509-24.

13. Vranckx P, Valgimigli M, Eckardt L, Tijssen J, Lewalter T, Gargiulo G, et al. Edoxaban-based versus vitamin $\mathrm{K}$ antagonist-based antithrombotic regimen after successful coronary stenting in patients with atrial fibrillation (ENTRUST-AF PCI): a randomised, open-label, phase 3b trial. Lancet. 2019;394(10206):1335-43.

14. Yasuda S, Kaikita K, Akao M, Ako J, Matoba T, Nakamura M, et al.; AFIRE Investigators. Antithrombotic therapy for atrial fibrillation with stable coronary disease. $N$ Engl J Med. 2019;381(12):1103-13.

15. Ruff CT, Giugliano RP, Braunwald E, Hoffman EB, Deenadayalu N, Ezekowitz MD, et al. Comparison of the efficacy and safety of new oral anticoagulants with warfarin in patients with atrial fibrillation: a meta-analysis of randomised trials. Lancet. 2014;383(9921):955-62.

16. Warfarin Antiplatelet Vascular Evaluation Trial Investigators; Anand S, Yusuf S, Xie C, Pogue J, Eikelboom J, Budaj A, et al. Oral anticoagulant and antiplatelet therapy and peripheral arterial disease. $N$ Engl J Med. 2007;357(3):217-27.

17. Anand SS, Yusuf S. Oral anticoagulants in patients with coronary artery disease. J Am Coll Cardiol. 2003;41(4):S62-9.
18. Uthman I, Noureldine MA, Ruiz-Irastorza G, Khamashta M Management of antiphospholipid syndrome. Ann Rheum Dis. 2018; 78(2):155-61.

19. Ogawa H, Nakayama M, Morimoto T, Uemura S, Kanauchi M, Doi N, et al.; Japanese Primary Prevention of Atherosclerosis with Aspirin for Diabetes (JPAD) Trial Investigators. Low-dose aspirin for primary prevention of atherosclerotic events in patients with type 2 diabetes: a randomized controlled trial. JAMA. 2008;300(18):2134-41.

20. Belch J, MacCuish A, Campbell I, Cobbe S, Taylor R, Prescott R, et al.; Prevention of Progression of Arterial Disease and Diabetes Study Group Diabetes Registry Group; Royal College of Physicians Edinburgh. The prevention of progression of arterial disease and diabetes (POPADAD) trial: factorial randomised placebo controlled trial of aspirin and antioxidants in patients with diabetes and asymptomatic peripheral arterial disease. BMJ. 2008;337:a1840.

21. ASCEND Study Collaborative Group; Bowman L, Mafham M, Wallendszus K, Stevens W, Buck G, Barton J, et al. Effects of aspirin for primary prevention in persons with diabetes mellitus. $N$ Engl J Med. 2018;379(16):1529-39.

22. Crandall KM, Rost NS, Sheth KN. Prognosis in intracerebral hemorrhage. Rev Neurol Dis. 2011;8(1-2):23-9.

23. Bonner C, Patel P, Fajardo M, Zhuang R, Trevena L. Online decision aids for primary cardiovascular disease prevention: systematic search, evaluation of quality and suitability for low health literacy patients. $B M$ J Open. 2019;9(3):e025173.

24. Fontana M, Asaria P, Moraldo M, Finegold J, Hassanally K, Manisty CH et al. Patient-accessible tool for shared decision making in cardiovascular primary prevention: balancing longevity benefits against medication disutility. Circulation. 2014;129(24):2539-46.

25. Arnett DK, Blumenthal RS, Albert MA, Buroker AB, Goldberger ZD, Hahn EJ, et al. 2019 ACC/AHA guideline on the primary prevention of cardiovascular disease: executive summary: a report of the American College of Cardiology/American Heart Association Task Force on Clinical Practice Guidelines. J Am Coll Cardiol. 2019;74(10):1376-414

Peter Loewen, BSc(Pharm), ACPR, PharmD, FCSHP, RPh

Associate Professor

Collaboration for Outcomes Research \& Evaluation (CORE)

Faculty of Pharmaceutical Sciences

The University of British Columbia

Vancouver, British Columbia

Competing interests: None declared.

Funding: The author's work is partially supported by The University of British Columbia's David H MacDonald Professorship in Clinical Pharmacy. 